\title{
Conservation of illusion-distorted length and illusion strength'
}

If kindergartners, first and second graders maintained that the lengths of two equal sticks they had selected remained equal after being made to look unequal by the Müller-Lyer illusion, they were scored as conservers. Significant differences in illusion strength were found only between conservers and nonconservers in the kindergarten.

Piaget, Inhelder, \& Szeminska (1960), in a test of area conservation, presented children with two identical cardboard models of farm pastures and proceeded to add identical farm houses to each pasture, but on one pasture they were spread out, while on the other they were clustered together. The children were asked each time a pair of houses was added if the cows would have the same amount of grass to eat in each pasture. A transition stage between nonconservation and conservation was found in which Ss maintained that the pastures were equal up to a certain number of added houses, but after that point the contrary perception was apparently too great and Ss reverted to nonconservation by claiming that there was more grassland in the pasture with the closely grouped houses than in the other pasture.

Smedslund $(1963,1964)$ has argued that conservation may be an all-or-none phenomenon in which the strength of contrary perceptual cues is negligible. On the other hand, Murray (1965) indicated that a negative relationship might exist between conservation and an indirect measure of illusion strength, and Frank (Bruner, 1964) reported that young children appear overwhelmed by contrary perceptual cues and revert to nonconservation after having given logical conservation responses in perceptually favorable situations.

This study made a direct measure of illusion strength to test whether it was related to nonconservation. Subjects

All 31 kindergartners, 42 first-, and 46 secondgraders with mean ages of 5.76 years, 6.71 years, and 7.79 years, respectively, were tested individually. Materials

The materials for the length conservation test were: (1) 10 round white sticks, $5 \mathrm{~mm}$ in diameter, two of which were the same length $(21 \mathrm{~cm})$, four were unequally longer than $21 \mathrm{~cm}$ and the rest, shorter, (2) a black rectangular $(30 \mathrm{~cm} \times 50 \mathrm{~cm})$ composition board on which were glued three cardboard figures-the arrows and feathers of the Muller-Lyer figure in horizontal position. The two segments of the arrows and feathers were $5 \mathrm{~mm} \times 7 \mathrm{~cm}$ and at right angles to one another.
The apparatus used for measuring the strength of the illusion was a modified Judd apparatus manufactured by the Lafayette Instrument Company, in which the comparison stimulus was a $21 \mathrm{~cm}$ length, distorted by the feathered segment of the Muller-Lyer figure. Procedure

The experimenter took the equal sticks that the $\mathrm{S}$ had selected from the eight unequal ones and placed them uprightly side by side on the table to enable the $S$ to reconfirm their equality before the experimenter slowly placed them in the Muller-Lyer configuration to make their lengths appear unequal. One-half the Ss had the feathered figure on the left, and the rest had it on the right. Ss were asked:

Does this stick (experimenter pointed to the stick in the feathered configuration) look longer than this stick (experimenter pointed to the arrowed stick), does it look the same as this stick, or does it look shorter than this stick?

To nullify any leading influence the order of the alternatives (longer, shorter, the same length as) might have on the S's response, the order of the alternatives was varied randomly among the Ss. If a $\mathrm{S}$ answered that the sticks looked the same length, he was discarded from the experiment. Ss were asked a second question:

If the sticks were standing up the way they were before, would this stick (experimenter pointed to the stick in the feathered configuration) be longer than this stick (experimenter pointed to the other stick), would it be the same length as this stick, or would it be shorter than this stick?

Again, the order of the alternatives was varied randomly among the Ss.

Ss were seated $3 \mathrm{ft}$. from the Judd apparatus and told and shown that the feathered line could be moved; they were asked to say "Stop" when the line between the arrowheads and the line between the feathers were the same length. After the experimenter had extended his finger the exact length of the lines in question, the Ss were told that eight judgments would be needed. The comparison stimulus was moved by the experimenter in $2 \mathrm{~mm}$ steps, from different starting points, on eight trials counterbalanced for space and movement error by the following sequence of trial conditions: RO, LI, LO, RI, LI, RO, RI, LO, where R and L refer to the condition when the comparison stimulus was on the S's right or left, and $O$ and I refer to the condition when the comparison stimulus movement was started from the outside, that is when it was much longer than the standard stimulus, or inside, when it was much shorter than the standard stimulus. 


\section{Results}

Each $\mathrm{S}$ was scored as having conserved only if (1) he saw the Müller-Lyer illusion, and (2) despite seeing it, maintained that the sticks were the same length. If a $\mathrm{S}$ maintained that the sticks were unequal in length, he was scored, of course, as a nonconserver.

A median test (Siegel, 1956) was applied to the scores, and indicated a significant difference in conservation between the group above the median age (6.91 years) and the group below it $\left(\mathrm{X}^{2}=14.4, \mathrm{p}<.001\right)$ 。

The mean constant error (CE), the measure of illusion strength, was for each grade $2.06 \mathrm{~cm}, 2.10 \mathrm{~cm}$, and 2.11 $\mathrm{cm}$, kindergarten through second grade respectively. The Duncan Range Test (McGuigan, 1960) indicated that these means were insignificantly different from each other at the .05 level.

The mean constant error for nonconservers was 2.11 $\mathrm{cm}$ and for conservers it was $2.09 \mathrm{~cm}$, and the difference between these means was insignificant $(t=.086, p>.05)$. The mean constant errors and differences for conservers and nonconservers for each grade indicated that the only significant difference was between the conservers $(\mathrm{CE}=1.46 \mathrm{~cm})$ and nonconservers $(\mathrm{CE}=2.39 \mathrm{~cm})$ of the kindergarten. The difference between the means of $.93 \mathrm{~cm}$ was significant at the .05 level.

\section{Discussion}

That there was no significant difference in illusion strength between the older conservers and nonconservers indicates that for older children conservation and nonconservation are all-or-nothing phenomena in which the simple inequality of the lengths in question, regardless of the magnitude, is the critical stimulus.

That there was a significant difference in illusion strength, though not a large one, between young conservers and nonconservers suggests that the magnitude of the contrary perception was a factor in whether the young child conserved length. Halpern (1965), although she did not find an age relationship using only $20 \mathrm{Ss}$, found that conservers, who had used logic, but still tended to offer empirical justifications in terms of perceptual facts for their conservation judgments, made more errors in a transitivity problem when perception contradicted logic than did conservers who had logical deductive justifications for their responses. What may distinguish the empirically oriented conserver from the perceptually bound nonconserver is the magnitude of the perceptual distortion.

What is needed is more research on (1) the relationship between perceptual processes and conservation, such as Nodelman's contention (1965) that nonconservers are field dependent, and on (2) the exact nature of the various kinds of length conservation.

\section{References}

Bruner, J. The course of cognitive growth. Amer. Psychologist, $1964,19,1-15$.

Halpern, Esther. The effects of incompatibility between perception and logic in Piaget's stage of concrete operations. Child Develpm., 1965, 36(2), 491-498.

McGuigan, F. Experimental psychology: A methodological approach. Englewood Cliffs, N. J.: Prentice-Hall, 1960.

Murray, F. Conservation of illusion-distorted lengths and areas by primary school children. J. educ. Psychol., 1965, 56, 62-66.

Nodelman, Cynthia. Conservation of substance and field-independence. Grad. Res. Educ. related Disciplines. 1965, 1, 3-34.

Piaget, J, Inhelder, Barbel, \& Szeminska, Alina. The child's conception of geometry. New York: Basic Books, 1960.

Siegel, S. Nonparametric statistics for the behavioral sciences. New York: McGraw-Hill, 1956.

Smedslund, J. Patterns of experience and the acquisition of conservation of length in children. Scand. J. Psychol., 1963, 4, $257-264$.

Smedslund, J. Concrete reasoning: A study of intellectual development. Monogr. Soc. Res. Child Develpm., 1964, 29, No. 93.

\section{Note}

1. The cooperation of the faculty and students of the Lida Lee Tall Laboratory School of Towson State College in Baltimore, Maryland was greatly appreciated. 